\title{
ANAESTHESTIC MANAGEMENT OF ELDERLY PATIENT WITH CORONARY HEART DISEASE AND COPD POSTED FOR SHOULDER DISARTICULATION SUFFERING FROM METASTATIC SQUAMOUS CELL CARCINOMA IN UPPER 1/3 OF HUMERUS UNDER COMBINED CERVICAL AND INTERSCALENE BLOCK
}

\author{
A. Naveen Kumar' ${ }^{1}$ S. Jagadeeshacharulu²
}

\section{HOW TO CITE THIS ARTICLE:}

A. Naveen Kumar, S. Jagadeeshacharulu. "Anesthetic Management of Elderly Patient with Coronary Heart Disease and COPD posted for Shoulder Disarticulation Suffering from Metastatic Squamous Cell Carcinoma in Upper 1/3 of Humerus under Combined Cervical and Interscalene Block". Journal of Evolution of Medical and Dental Sciences 2014; Vol. 3, Issue 14, April 07; Page: 3709-3713, DOI: 10.14260/jemds/2014/2348

\begin{abstract}
We present a case of elderly patient aged 60 years posted for left shoulder disarticulation who is suffering from metastatic squamous cell carcinoma in upper $1 / 3$ of left humerus with coronary heart disease and COPD as comorbid factors. Coronary heart disease and COPD are the two most common and dangerous risk factors contributing to high morbidity and mortality during surgery. General Anaesthesia in patients with coronary heart disease and COPD results in high mortality during surgery. Perioperative optimization of these high-risk patients deserves a thorough understanding of the patient cardiopulmonary diseases as well as the respiratory consequences of surgery and anesthesia. In order to avoid high morbidity and mortality associated with General Anaesthesia in patients with coronary heart disease and COPD, we opted for shoulder disarticulation surgery under continuous combined cervical and interscalene block. This case highlights the advantage of the regional nerve blocks over General Anaesthesia in patients with coronary heart disease and COPD.
\end{abstract}

KEYWORDS: Coronary heart disease, COPD, cervical plexus block, interscalene block, general anesthesia complications in CAD and COPD.

INTRODUCTION: We as Anaesthesiologists are always worried about the occurrence of recurrent Ischemic attacks and irreversible Bronchospasm during General Anaesthesia which can lead to high mortality rates. ${ }^{1-3}$ Aim of the study is to highlight the safety of combined cervical and interscalene block in high upper limb surgery with associated high risk comorbid factors. ${ }^{1-3}$ Continuous interscalene block provided excellent post-operative analgesia which prevented the Bronchospasm and ischemic attacks.

CASE REPORT: A 60 year old male patient weighing $68 \mathrm{kgs}$ was admitted to our hospital with severe intractable pain over left shoulder radiating to the whole limb.

On examination left shoulder and left elbow movements were severely restricted. On palpation bony hard swelling of size $10 \times 8 \mathrm{~cm}$ felt over left shoulder. No history of trauma was present. Palpable swelling is noted in the midline of neck which moves with deglutition and not moving on protrusion of the tongue. Patient was chronic smoker since 25 years. No history of hypertension, diabetic, and coronary heart disease. History of exertional dysponea of grade III, cough and pedal edema were present. 
The patient was evaluated in Pre Anaesthestic checkup for fitness for surgery with investigations like complete Blood picture, chest X ray, ECG, 2 D Echo and Pulmonary Function Tests.

On investigations we found that patient is suffering with Coronary heart Disease and COPD and is a high risk case for surgery under General anaesthesia.

Systemic examination revealed normal heart sounds, decreased breath sounds on right side of lung. Bronchial breathing present.

ECG shows ST segment depression, T wave inversion L2, L3 and AVF leads.

Chest X Ray shows Right upper lobe Pulmonary Tuberculosis and COPD changes.

Echocardiography shows RWMA, Akinesia of anterior septum, anterior wall with Ejection Fraction 37\%.

Pulmonary Function test show mixed blockage with small air way obstruction with poor response to bronchodilator therapy.

On investigation like X Ray left Shoulder, CT scan left shoulder, Truecut biopsy left shoulder, Ultra sound Thyroid patient is found to be suffering from metastatic Squamous cell Carcinoma in Upper 1/3 of Left Humerus.

In order to relieve the patient from severe intractable left upper limb pain patient was posted for left shoulder disarticulation surgery.

Patient is on Bronchodilators. Tab Deriphyllin 1 tid, Tab Ecosprin $150 \mathrm{mg}$ OD.

Bronchodilators continued and Ecosprin stopped 2 days before surgery.

After obtaining high risk consent from patient in view of old age, CAD, COPD we opted for shoulder disarticulation under combined continuous cervical and Interscalene Block 4,5

In operating room patient NIBP 136/84, HR 84/mt, RR 16/mt, SPO2 90\%

$100 \%$ Oxygen inhalation by Face mask started.

Multi-channel monitoring SPO2, PR, NIBP, 6 lead ECG started.

18 gauge IV Cannula was secured on right dorsum of hand.

Pre medication of Midazolam $1 \mathrm{mg} I \mathrm{~V}$, Ondansetron 4mg was given before block.

PROCEDURE:30 $\mathrm{ml}$ of $0.25 \%$ Bupivacaine +10 of 1\% Lignocaine used for administration of block.

Under aseptic precautions after local infiltration of skin with local anesthetic solution, left deep Cervical Plexus block achieved by injecting $15 \mathrm{ml}$ of combined 1\% Lignocaine and 0.25\% Bupivacaine after contact with C2, C3, and C4transverse process and after eliciting paresthesia with 23 gauge needle.

Left superficial Cervical Plexus block achieved by injecting $5 \mathrm{ml}$ combined 1\% Lignocaine and $0.25 \%$ Bupivacaine at the point where external Jugular vein crosses the Posterior border of Sternocleidomastoid muscle.

Under aseptic precautions after local infiltration of skin with local anesthetic solution left Interscalene block is achieved by injecting $20 \mathrm{ml}$ of combined $1 \%$ Lignocaine and $0.25 \%$ Bupivacaine after eliciting paresthesia with 18 gauge needle. Brachial Plexus Catheter passed through the 18 gauge needle and secured in the interscalene space for post-operative analgesia.

After 10 minutes of combined interscalene and cervical plexus block effect was adequate. Butorphanol 2mg IV given.

Surgery started after 20 minutes of block.

Anaesthesia is adequate and patient is comfortable. 
1 litre of Ringer Lactate and $500 \mathrm{ml}$ of 5\% Dextrose was administered during surgery which lasted for $1 \mathrm{hr} 10$ minutes. Hemodynamics well maintained during surgery.

Intra operative period was uneventful.

Post operatively patient was conscious and coherent. SPO2 97\%, PR 74/mt, NIBP 130/74.

After satisfactory recovery patient was shifted to ICU where patient was given Butorphanol2 mg given for every $6 \mathrm{hrs}$. combined with $6 \mathrm{ml}$ of $0.125 \%$ Bupivacaine for every $4 \mathrm{hrs}$. for $48 \mathrm{hrs}$. for post- operative analgesia through Brachial plexus catheter.6 Patient was monitored regularly for evidence of Ischemic attacks ${ }^{7}$ and bronchospasm.,

After 48 hrs Brachial plexus catheter was removed and patient shifted to post-operative ward. Rest of the hospital stay was uneventful.

DISCUSSION: The prime consideration in managing our case was to avoid bronchospasm and maintaining hemodynamic stability during surgery.8, 9 The case study shows the safety and efficacy of combined cervical and interscalene block in shoulder surgery in patients with CAD and COPD who have higher morbidity and mortality under General anaesthesia.10-13

Experimental studies demonstrated General Anaesthesia in patients with COPD carries high morbidity and mortality even under intravenous bronchodilator therapy. Continuous Brachial plexus catheter provided the patient pain free period for $48 \mathrm{hr}$. In ICU stay the need for nebulisation does not arise.

In patients with COPD who were given General Anaesthesia required more prolonged ICU stay with extensive nebulisation therapy. Combined interscalene and cervical plexus block reduced the ICU stay of the patient and no nebulisation required in the ICU stay.14,15

We didn't encounter complications of cervical and interscalene block like Phrenic nerve palsy, Horner's syndrome inadvertent intravascular, subarachnoid or epidural spread. Forced vital capacity is measured before block, 10 minutes after block and in the recovery room. There were no significant changes in the forced vital capacity signifying there was no compromised respiratory function. Patient is comfortable and no respiratory difficulty and is very much tolerable for surgery.

We used low concentration of Bupivacaine for block as lower concentration has lesser cardiovascular toxicity compared to higher concentrations, and systemic toxicity is low in lower concentrations than higher concentrations in accidental intravascular, subarachnoid and epidural spread. Low concentration and higher volumes have more successful blockade than with high concentrations and lower volumes. Shoulder disarticulation doesn't need much muscle relaxation. Only sensory blockade is sufficient. So usage of lower concentrations in higher volumes is justified.

CONCLUSION: Combined interscalene and cervical plexus block can be selected as anaesthetic technique for high risk undergoing shoulder, upper limb surgeries, and clavicular surgeries. Its routine use as a conventional technique needs further evaluation and studies.

\section{REFERENCES:}

1. Nancy A. Nussmeier, Michael C. Hauser, Muhammad F. Sarwar, Alina M. Grigore, Bruce E. Searies. Anesthesia for cardiac Surgical Procedures.; Ronold D. Miller; 7th edition Miller's Anaesthesia; Churchill Livingstone ; 2010.1923-1927;

2. Shamsuddin Akhtar. Ischemic HEART disease 11-22, Viji Kurup Respiratory Diseases.188194. 
Roberta L. Hines, Katherine E. Marschall, $5^{\text {th }}$ edition: Stoelting's Anaesthesia \& Co- Existing Disease; Reed Elsevier India private limited: 20122002 Jun; 16(2):188-194.

3. Tara M. Hata and John R. Moyers. Preoperative Patient Assessment and Management.188194. Ban C.H Tsui and Richard W. Rosenquist: Peripheral Nerve Blockade: 963-964. Paul G. Barash : 6th edition: Clinical Anaesthesia ; Lippincott Williams \& Wilkins ; 2010.572-578;

4. Borgeat A, Ekatodramis G. Anaesthasia for shoulder surgery. Best Pract Res Clin Anaesthesiology.2002 Jun; 16(2):211-25.

5. Borgeat A, Dullenkopf A, Ekatodramis G Nagy L. Evaluation of the lateral modified approach for continuous interscalene block after shoulder surgery. Anesthesiology. 2003 Aug; 99(2): 436-42.

6. Gruber EM, T Schernko EM, Ther Umsch. Anaesthesia and postoperative analgesia in older patients with chronic obstructive pulmonary disease: special considerations.., 1999 Mar; 56(3):151-6. Drugs Aging 2003;20(5):347-60.

7. Warltier DC, Pagel PS \& Kersten JR. Approaches to the prevention of perioperative myocardial ischemia Anesthesiology 2000; 92: 253-259.

8. A Rudra, Sudipta Das. Postoperative pulmonary complications. March-April 2006, 50(2):8989.

9. Licker M, Schweizer A, Ellenberger C, Tschopp JM, Diaper J, Clergue F. Perioperative Management of patients with COPD: Int J Chron Obstruct Pulmon Dis. 2007; 2(4):493-515.

10. Kroenke K, Lawrence VA, Theroux JF, et al. Operative risk in patients with severe obstructive pulmonary disease. Arch Intern Med. 1992; 152:967-71. [PubMed].

11. Sin DD, Wu L, Man SF. The relationship between reduced lung function and cardiovascular mortality: a population-based study and a systematic review of the literature. Chest.2005; 127:1952-9. [PubMed].

12. American College of Physicians. Guidelines for assessing and managing the perioperative risk from coronary artery disease associated with major non-cardiac surgery. Annals of Internal Medicine 1997; 127: 309-312.

13. Farid I, Litaker D \& Tetzlaff JE. Implementing ACC/AHA guidelines for the preoperative management of patients with coronary artery disease scheduled for non-cardiac surgery: effect on perioperative outcome. Journal of Clinical Anesthesia 2002; 14: 126-128.

14. Hofmann-Kiefer K, Eiser T, Chappell D, Leuschner S, Conzen P, Schwender D. Does patientcontrolled continuous interscalene block improve early functional rehabilitation after open shoulder surgery? Anesth Analg. 2008 Mar;106(3):991-6, table of contents. doi: 10.1213/ane. 0b013e31816151ab.?,

15. Fredrickson MJ, Krishnan S, Chen CY. Postoperative analgesia for shoulder surgery: a critical appraisal and review of current techniques. Anaesthesia. 2010 Jun; 65(6):608-24. doi: 10.1111/j.1365-2044.2009.06231.x. 


\section{CASE REPORT}
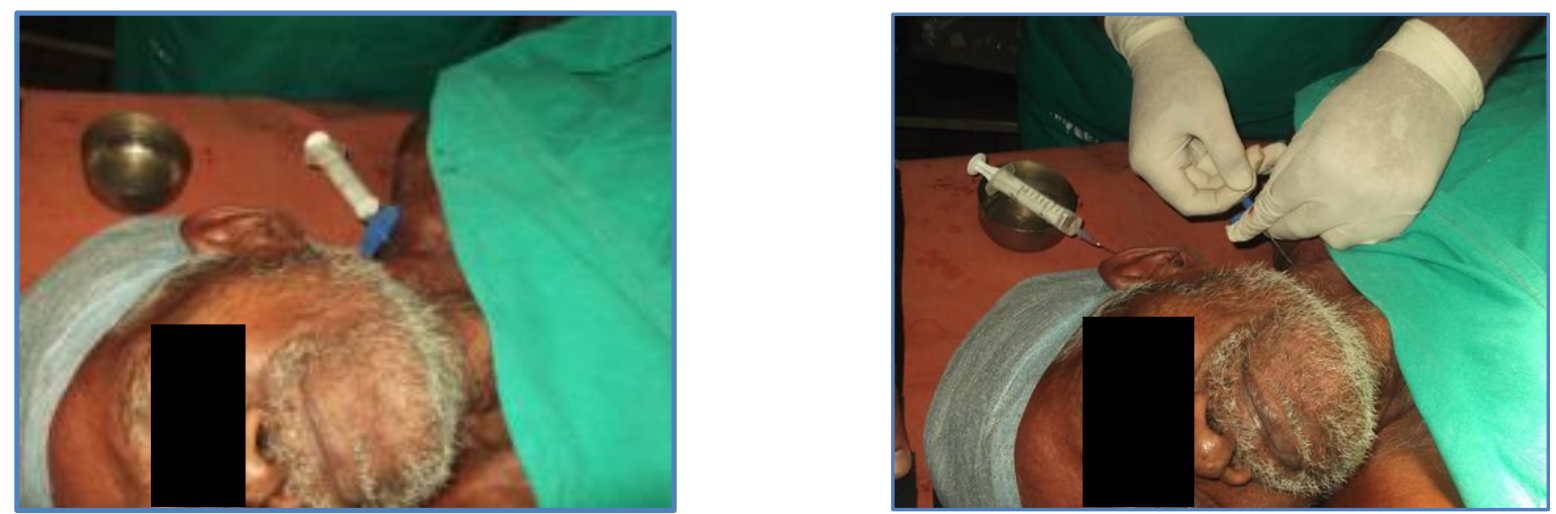

\section{Continuous interscalene block}

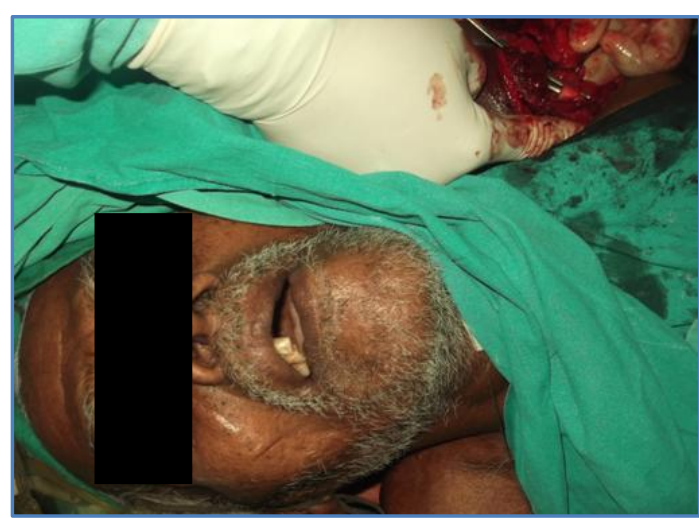

Intra operative photo

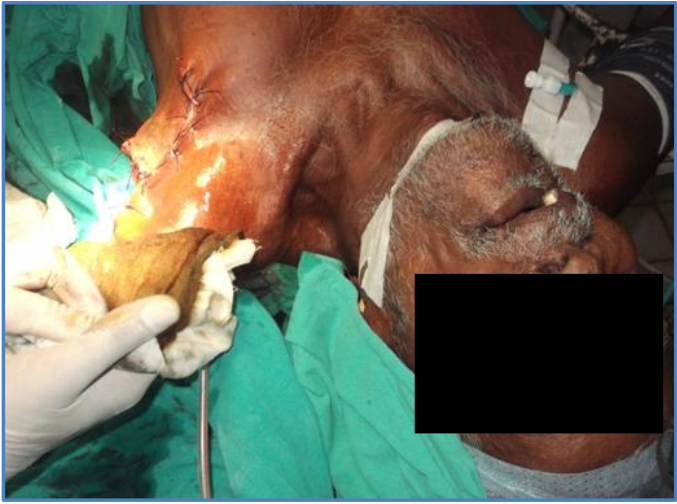

post operative photo

\section{AUTHORS:}

1. A. Naveen Kumar

2. S. Jagadeeshacharulu

\section{PARTICULARS OF CONTRIBUTORS:}

1. Incharge Professor, Department of Anaesthesia, Government Medical College, Ananthapuramu.

2. Assistant Professor, Department of Anaesthesia, Government Medical College, Ananthapuramu.

\section{NAME ADDRESS EMAIL ID OF THE} CORRESPONDING AUTHOR:

Dr. A. Naveen Kumar,

15/51, Flat No. 301,

Jayam Paradise,

Kamalanagar, Anathapuramu - 515001,

Andhra Pradesh.

E-mail: ramyaraj27@gmail.com

Date of Submission: 08/03/2014.

Date of Peer Review: 10/03/2014.

Date of Acceptance: 21/03/2014.

Date of Publishing: 05/04/2014. 